\title{
A WEB-BASED SMART TELECARE SYSTEM FOR EARLY DIAGNOSIS OF HEART ATTACK
}

\author{
S.A. Hosseinpour ${ }^{1}$, M.R. Delavar ${ }^{2}$, H. Hasani Baferani ${ }^{3}$ \\ ${ }^{1}$ GIS Dept., School of Surveying and Geospatial Engineering., College of Engineering., University of Tehran, Tehran, Iran - \\ s.alihosein.p@ut.ac.ir \\ ${ }^{2}$ Center of Excellent in Geomatic Engineering in Disaster Management, School of Surveying and Geospatial Engineering., College \\ of Engineering., University of Tehran, Tehran, Iran. - mdelavar@ ut.ac.ir \\ ${ }^{3}$ Medical School, Iran University of Medical Sciences, Tehran, Iran - drhasanibafrani@gmail.com
}

Commission VI, WG VI/4

KEY WORDS: Telecare, Smart City, Hearth Attack, Geospatial Services, Regression, Real Time Application

\begin{abstract}
:
Acute coronary syndrome which could lead to a heart attack is a common and dangerous disease in many parts of the world. Telecare can accelerate the diagnosis of the disease to provide user information including his/her location in an emergency to a support unit, to reduce the treatment time. Therefore, it is essential to develop a smart telecare system that monitors the status of the user automatically in real-time. This paper has proposed and implemented a web-based smart telecare system. The architecture of this system is based on an architecture for smart care in a smart city. This system receives information from the user and uses linear regression to detect acute coronary syndrome at the initial stage of the disease. This information is descriptive and selected according to the opinion of the cardiologist. Also, in case of diagnosis of acute coronary syndrome, the user's location is determined and sent to a support unit via email. The accuracy of this system is $77.5 \%$. This accuracy is acceptable compared to the same system that predicts myocardial infarction. As the proposed system, unlike the comparator system, does not use electro cardio graphic signals (ECG), it can significantly reduce the time of diagnosis of acute coronary syndrome and its complications through early diagnosis of the disease and its notification. The innovation of this research is the presentation of an intelligent decision maker system that reports the hearth attack to the decision support system via an email message.
\end{abstract}

\section{INTRODUCTION}

Acute Coronary syndrome (ACS) which could lead to a heart attack is more prevalent and dangerous than other types of heart disease (Soltani et al. 2016). The timely diagnosis and notice of the disease is very important for immediate treatment and for the survival of the affected person (Soltani et al. 2016). Statistics shows that most people with the disease are not timely diagnosed (Soltani et al., 2016). Therefore, traditional medical methods that are limited to in-person examinations cannot support this condition well. Telecare and smart health are the answer to this. ACS is a term that describes an acute ischemic insult to the myocardium resulting from sudden reduction in coronary blood flow (Ahmad and Ali 2019). The leading symptom that initiates the diagnostic and therapeutic cascade in patients with suspected ACS is chest pain, one major criteria is typical rise and gradual fall in cardiac biomarkers (troponin or CKMB) in addition to one or more of the following (Ahmad and Ali 2019):

1. Symptoms of ischemia.

2. ECG changes.

3. Imaging evidence of new or presumed new loss of viable myocardium or regional wall

motion abnormality.

4. Intracoronary thrombus detected on angiography or autopsy

Telecare is the provision of services at the patient's home or wherever the patient is present (Safdari et al. 2012). Telecare is a component of smart healthcare. Smart healthcare is a combination of traditional medicine, smart biological sensors, wearable devices, information and communication technology (ICT) and smart systems which aims to make online decisions about patient health (Mohanty 2016). Using smart healthcare, the patient's data can be made available in a smart hospital. Medical technicians, nurses and doctors can access online patient's information without losing details and can decide on the patient's condition (Mohanty 2016). The most important characteristics required for smart healthcare system are real time monitoring, on-time delivery, higher sensitivity and embark on intelligent processing (Sundaravadivel et al. 2018). Also, The most important attributes of smart healthcare system are Location an identification (Sundaravadivel et al. 2018). One of the services available through smart healthcare is the community heath monitoring (Sundaravadivel et al. 2018). The smart healthcare is one of the key elements of a smart city.

Smart city is where traditional networks and services use information, tele-communication and digital technologies to become more flexible, efficient, and stable, in order to improve their performance for citizens (Gaur et al. 2015; Mohanty 2016). Some of the most important parts of the smart city are smart building, smart transportation, smart energy, smart healthcare and smart technology according to Fig. 1 (Gaur et al. 2015). One of the key features of smart city is the promotion of quality of life, which is one of the goals of achieving smart city. Smart system architecture in a smart city is according to Fig. 2 (Gaur et al. 2015). Using this architecture, one can provide high-level online services to individuals. 


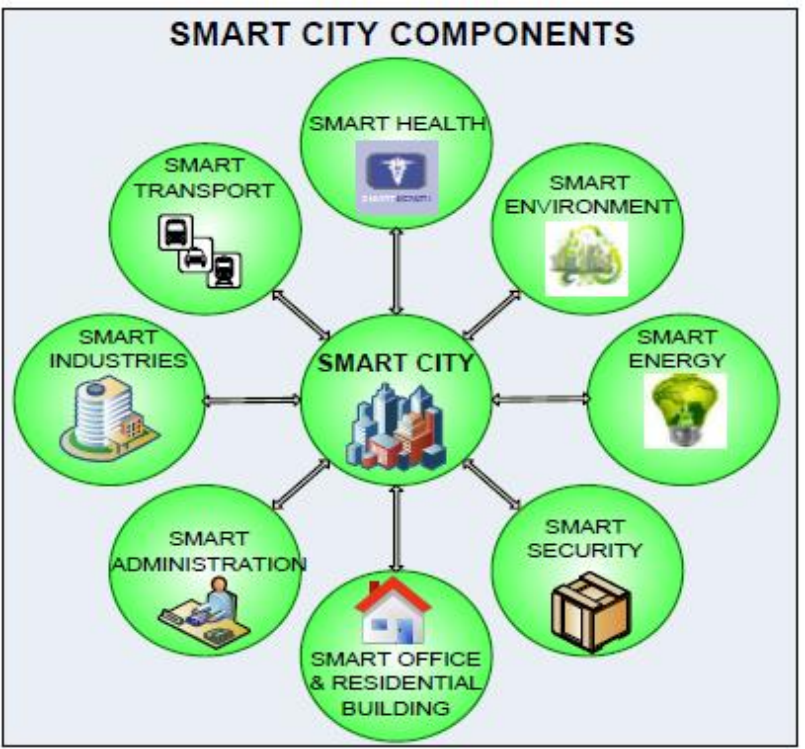

Figure 1. Smart City Components (Gaur et al. 2015)

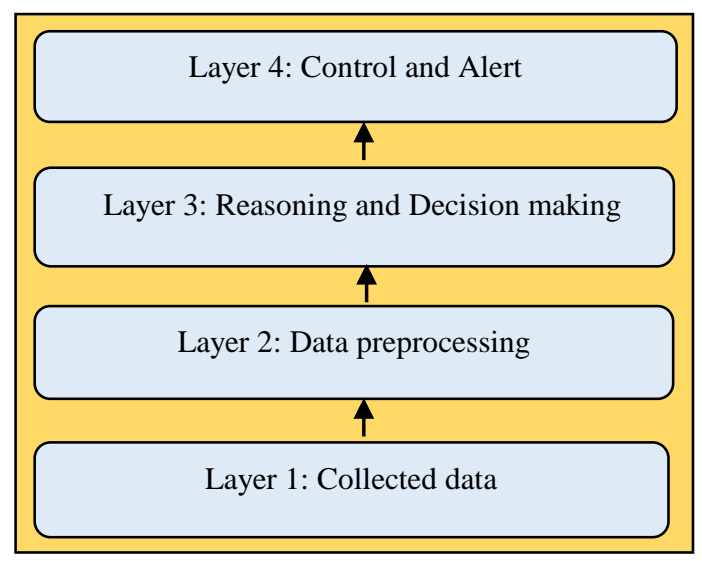

Figure 2. Smart system architecture in a smart city (Gaur et al. 2015)

Artificial intelligence (AI) techniques have been applied in cardiovascular $(\mathrm{CV})$ medicine to explore novel genotypes and phenotypes in existing diseases, improve the quality of patient care, enable cost-effectiveness, and reduce readmission and mortality rates (Krittanawong et al. 2017). AI will not replace physicians, but it is important that physicians know how to use AI sufficiently to generate their hypotheses, perform big data analytics, and optimize AI applications in clinical practice to bring on the era of precision CV medicine (Krittanawong et al. 2017). Machine learning are promising and can potentially change the way in which medicine is practiced, but physicians need to be prepared for the upcoming AI era (Krittanawong et al. 2017).

The use of the Web for telemedicine applications seems nowadays a compulsory solution because the Web has become a standardized infrastructure for giving access to sophisticated telemedicine applications from virtually any machine and operating system (Bellazzi et al. 2001). A Simplified Framework for Web-based Telemedicine System is proposed according to Fig. 3 (Olayinka et al. 2018). The location-aware telecare system is a new approach in telemedicine (Boulos et al. 2007). This type of system in emergency situations allows the support system to be aware of user position (Boulos et al. 2007).

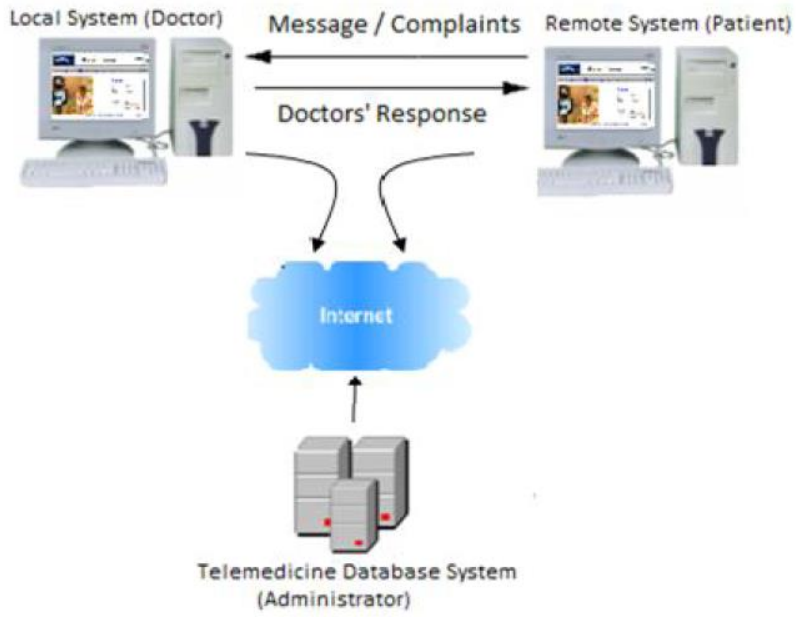

Figure 3. Simplified Framework for Telemedicine System (Olayinka et al. 2018)

Therefore, ACS diagnosis in a smart, remote and web-base way and using AI, as well as informing the patient about his/her situation and location with respect to the medical service providers, such as emergency centers, are the vital geospatial and real-time application services in the smart city. So the main concern of this research is to reduce the time to diagnose the ACS in the smart telecare system.

Research in this area can be divided into two categories. The first category is research that has provided a method for detecting or predicting ACS using different intelligence and data. VanHouten and al. have compared the random forest, elastic net and the regression in prediction in ACS. (VanHouten et al. 2014). According to the results of this study, the efficiency of these methods is $0.848,0.818$ and 0.810 , respectively. In another study, Bricol et al compared the SVM, ANN, Navy Bays and regression methods for predicting ACS (Berikol, Yildiz, and Özcan 2016). According to the results of this study the prediction accuracy of each of these methods is $99.13 \%, 99.10 \%, 88.75 \%$, and $91.26 \%$, respectively. Gambar et al., Have compared linear kernel support vector machine and radial basis function neural network to create a decision support system for heart disease diagnosis (Ghumbre, Patil, and Ghatol 2011). According to the results of this study the accuracy of the support vector machine is $86.42 \%$ and the accuracy of the artificial neural network is $80.81 \%$. Manikandan, in his research, developed a system for the diagnosis of myocardial infarction using supervised learning and Bayesian method, with the accuracy of 81 (Manikandan 2017). According to Purusothaman and Krishnakumari research, decision tree methods, k-nearest neighbor11, artificial neural network, support vector machine, and Bayes have 76\%, 58\%, 85\%, 86\%, and $69 \%$ accuracy in predicting heart disease (Purusothaman and Krishnakumari 2015). In most of these studies data such as ECG, chest pain, shortness of breath, arm pain, addiction, diabetes and heart rate have been used.

The second category is research that deals with designing, proposing, or developing a medical system or telemedicine to diagnose, monitor, or inform ACS. Lamberti et al. designed a web-based system for dynamic content delivery and consulting and medical data correction services (Lamberti et al. 2002) . The system provides access to the patient's electronic records using browser-equipped devices. Carral et al. designed a webbased telemedicine system to monitor the blood sugar of pregnant women with diabetes (Carral et al. 2015). In this 
system, pregnant women can record their blood glucose levels after measurement to be checked by specialists. This will help them manage their situation more and better and require less inperson visits. Manikandan introduced a web-based system for predicting ACS (Manikandan 2017) .The system includes a web page to retrieve data from the user, a server for data analysis, and a database for storing data. Hoyo et al. also designed a webbased system to monitor complex bowel disease (Del Hoyo et al. 2018) . The system asks the user questions and, according to the results of the study, this web-based system, TECCU, is a safe strategy to improve health outcomes in patients with IBD and reduce the use of health care resources. Kamel Boulos et al. introduces CAALYX - Complete Ambient Assisted Living Experiment, an EU-funded project that aims at increasing older people's autonomy and self-confidence by developing a wearable light device capable of measuring specific vital signs of the elderly, detecting falls and location, and communicating automatically in real-time with his/her care provider in case of an emergency, wherever the older person happens to be, at home or outside (Boulos et al. 2007).

In this research, we are attempting to answer the following questions: What are the data needed for early diagnosis of acute cardiac syndrome? What is the method of performing a primary diagnosis of acute cardiac syndrome in a smart way? How should the system be implemented? Therefore, the main goal of this research is to provide a smart web-based telecare system for the early diagnosis of acute coronary syndrome at various locations and announcing emergency notice to the appropriate health centers to follow-up the case. So the hypothesis of this research is that the proposed system can accelerate the diagnosis of the ACS. It is assumed in this research that linear regression can be used to handle the concerned data. In order to evaluate this research, its results are compared with those of the research undertaken by Manikandan (2017).

The scenario of this research is as follows: The user feels some of the warning signs. Then goes to the tele-care system via the Internet. The user uploads the requested information and examines the status of the occurrence or absence of acute coronary syndrome.

Section 2 describes the proposed method. Section 3 describes the implementation of proposed method. Section 4, reports the results of the research. In Section ${ }^{\circ}$, the final conclusion is presented.

\section{PROPOSED METHOD}

\subsection{Title}

According to the architecture provided for smart systems in Fig. $Y$ and framework for telemedicine system in Fig. 3, the proposed Smart Telecare system is designed in according to Fig. 4. As only descriptive data is used in this system, there is no stage for data pre-processing. As shown in Fig. 4, a website was designed and implemented to implement the system, which includes the following parts:

1. First, the information required for early diagnosis of ACS is obtained from the user through Form 1. According to a cardiologist, these data include age, sex, history of heart disease, diabetes, blood lipids, history of hypertension, chest pain, type of person's physical activity in the time of occurrence of warning signs, pain in the hands, arm, jaw, shoulder or back, stomach pain, weakness and fatigue, anxiety, nausea or vomiting, sweating, shortness of breath, palpitations and smoking have been selected.
2. The information obtained is processed using a Regression according to Equation 1 (Harrington 2012), based on that the user is classified into two groups of patients with acute cardiovascular or non-acute syndrome. Regression is implemented separately in MATLAB software using medical records of people with acute and noncoronary syndrome, then its coefficients are introduced at this stage to web-based system according to Fig. 5.

$$
z=W_{0} X_{0}+W_{1} X_{1}+W_{2} X_{2}+\ldots+W_{n} X_{n}
$$

where

$$
\begin{aligned}
& \mathrm{Z}=\text { user class } \\
& \mathrm{X}_{\mathrm{i}}=\text { data value } \\
& \mathrm{W}_{\mathrm{i}}=\text { coefficients }
\end{aligned}
$$

3. If a person is diagnosed as non-affected, he or she will be shown a non-response. Otherwise, he/she will be notified of the occurrence of ACS and will be asked to send the information.

4. By clicking the specified icon, the user is redirected to another page. There, he/she will be asked to enter his/her information including his/her name, surname, age and the number of the closest construction unit in second form $\mathrm{He} / \mathrm{she}$ will also be asked to specify his/her position on the map shown and to push the submit key. Afterwards, the information in the step 4 is sent by email to a support unit that can be an emergency unit or one of the relatives of an individual. This information is also recorded in a database. Finally, the message of success in sending the information is shown to the individual.

Auto diagnosis is a key feature of the intelligence of the proposed system. The user position is the most important spatial data used in this system to inform the decision support unit. In order to evaluate the proposed system, Its features will be compared with the system designed by Manikandan (2017).

\section{IMPLEMENTATION}

The implementation of the proposed system consists of two steps. The first step is to calculate the regression coefficients and the second is to build a web-based system. In the following, the study area and samples for calculating regression coefficients are described first. Then the implementation steps will be outlined.

\subsection{Study Area and Samples}

The study areas are Musa bin Jafar hospital in Quchan city and Shahid Lavasani in metropolitan Tehran. The samples used in this study are patients referred to the two hospitals. The number of 38 medical records of patients with acute heart syndrome, 18 medical records of gastric patients and 26 cases of asthma attack belonging to different months of 2016, have been received from Musa bin Jafar Hospital. All these cases are related to the residents of Quchan and its suburbs. 26 medical records of patients with acute heart syndrome were obtained from the Shahid Lavasani Specialty Hospital. All of these patients reside in different areas of Tehran metropolis. The required information is extracted from the log files. All samples are used to determine the status of individuals by regression. In total, 190 samples were collected. $20 \%$ of the samples are randomly used for testing and the rest for training. For a balanced distribution of test and training samples between the 4 defined groups, the samples are selected so that that $20 \%$ of each group of individuals is selected. 6 cases of asthma patients, 


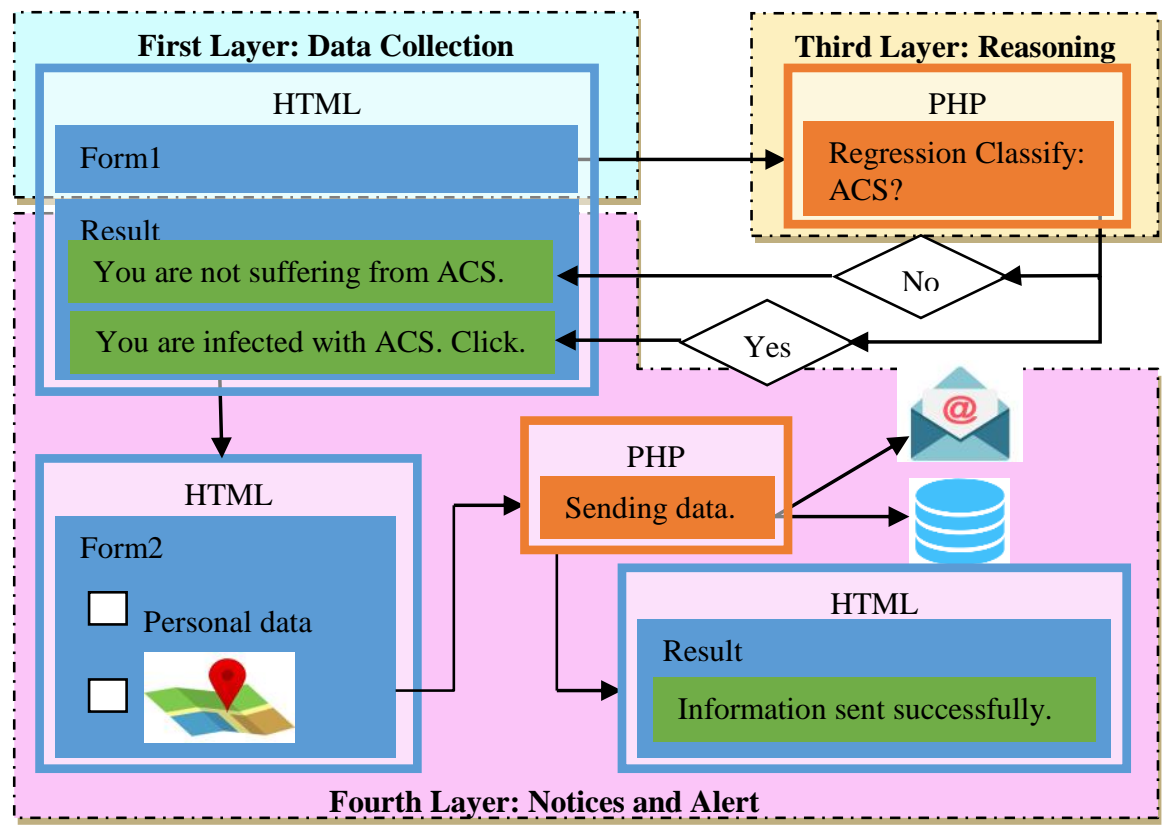

Figure 4. Proposed system architecture and component

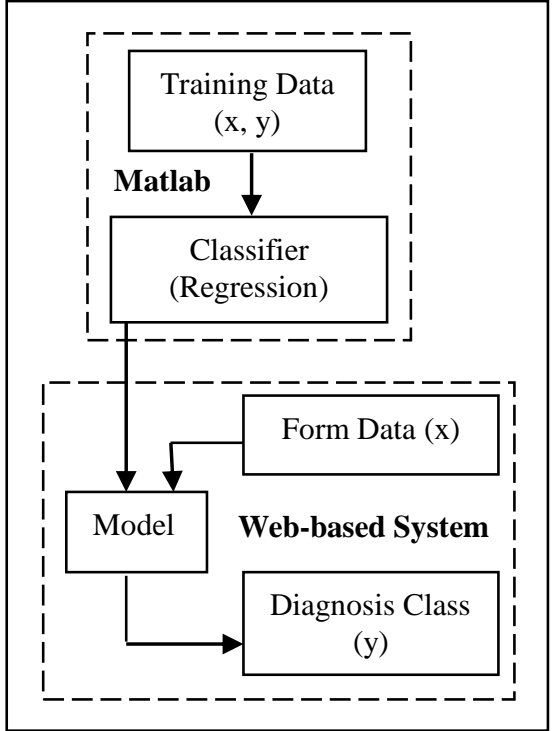

Figure 5. Accessing classifier via web interface

4 patients with gastric gastritis, 13 patients with acute heart syndrome, and 17 healthy subjects were selected.

\subsection{System Implementation}

3.2.1 Calculation of regression coefficients: Ready functions are used to calculate regression coefficients in MATLAB software. The pseudo-code required for this purpose is shown in Fig. 7 . For this purpose, the samples are divided into two categories. Category -1 means that a person does not have ACS. Category 1 means the person has ACS. The criteria for this choice are the diagnosis of a physician in the medical record. The required data will also be normalized.

\begin{tabular}{|ll|}
\hline 1. & Import input data matrix $\mathrm{x}$. \\
2. & Normalized $\mathrm{x}$. \\
3. & Import output class vector $\mathrm{y}$. \\
4. & Regression training with $(\mathrm{x}, \mathrm{y})$. \\
5. & Export regression coefficients. \\
\hline
\end{tabular}

Figure 6. The pseudo-code required for calculate regression coefficients.

3.2.2 System implementation: A web page was created using Wordpress software. In this layer the required information is taken from the user. Users can be redirected to the designed page by typing http://matlabing.ir/telemed into their browser. This page displays a questionnaire that the user must answer. The regression coefficients for the data obtained are already entered in the server. Using these coefficients and the user's response, their status is calculated and displayed. If the calculated condition is acute coronary syndrome, the user will be asked to click on the displayed image to move to the position submission page. After moving to the position submission page, the user must select their location on the map. In order to expedite the positioning, the user is asked to enter the name of their locality. The user then puts the marker in its position and enters the requested specification. After completing the specification and selecting the submit button, the complete user profile will be sent to the support via email. A confirmation message will also be sent to the user.

\section{RESULTES}

The specifications of the system are reported in Table 1 . The system uses a MySQL database with a storage capacity of 1000 megabytes and an Apache server. The system bandwidth is 100 MB. Since the volume of each web page in the system does not exceed $80 \mathrm{~kb}$, it can respond to at least 1000 users 

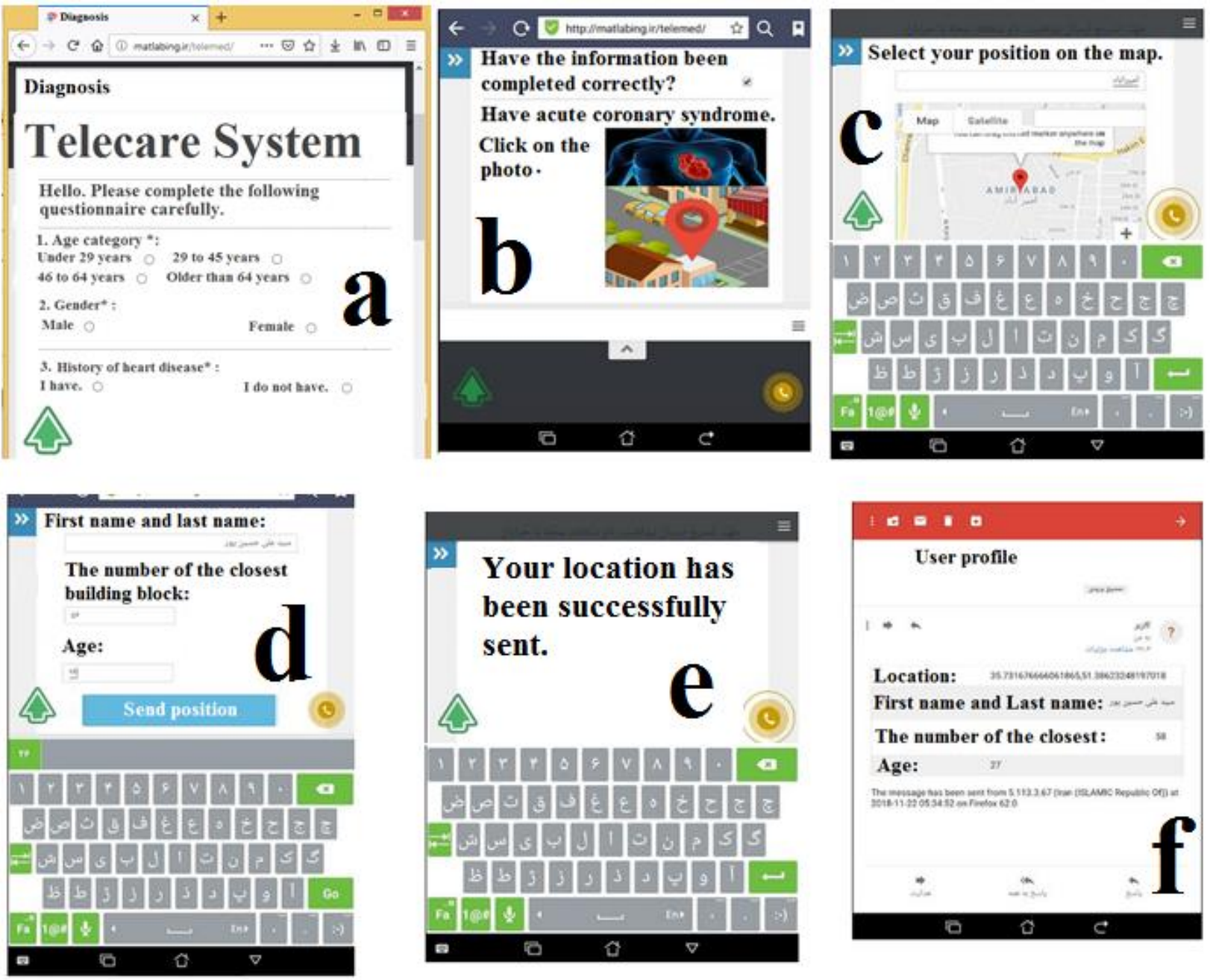

Figure 7. Some screenshots of prototype system at the time of sending information to the support system. a) By searching the http://matlabing.ir/telemed in the browser, the designed system will be displayed. A web page displays a questionnaire to the user. The user has entered the information and the system detected that the user is ill. b) The result of the diagnosis is shown to the user. In this case the user is diagnosed with ACS. c) The user specifies his/her location on the map. d) The user enters his/her other information. After selecting the submit time button, User information is sent to the support unit via email. e) If the information is transmitted correctly, the message of success in sending the information will be displayed to the user. f) Information is received by email.

simultaneously. It can also be used with laptops, tablets and smartphones. You only need to be connected to the internet to use it. The detection accuracy of this system is $77.5 \%$. Actually, of the 40 test samples, the proposed system correctly

\begin{tabular}{|c|c|c|c|}
\hline Accuracy ( \%) & $\begin{array}{c}\text { Storage } \\
\text { space (Mb) }\end{array}$ & Server & Database \\
\hline 77.5 & 1000 & $\begin{array}{c}\text { Apache } \\
2.2 .34 \\
\text { PHP } \\
5.3 .29\end{array}$ & $\begin{array}{c}\text { MySQL } \\
5.6 .41\end{array}$ \\
\hline $\begin{array}{c}\text { Communication } \\
\text { method }\end{array}$ & $\begin{array}{c}\text { Usable } \\
\text { platforms }\end{array}$ & $\begin{array}{c}\text { Bandwidth } \\
\text { (Mb) }\end{array}$ & $\begin{array}{c}\text { Decision } \\
\text { making } \\
\text { Method }\end{array}$ \\
\hline Internet network & $\begin{array}{c}\text { Laptops } \\
\text { Smartphone } \\
\text { Tablet }\end{array}$ & 100 & Regression \\
\hline
\end{tabular}

Table 1. Specifications of the proposed system determined the health status of 31 samples, As the doctor has specified in the patient's file. The system interface is as shown in Fig. 7. As shown in Fig. 7.a, the user is redirected to the system homepage by searching the system address in the browser. On this page, the necessary information will be obtained from the patient with a questionnaire. As shown in Fig.7.b, if the patient's condition is diagnosed with ACS, a message with the same content will be displayed in text and image to the patient, otherwise the message "You do not have ACS" will be displayed. If the patient is infected, they will be asked to click on the image. This will take the patient to the next page. As shown in Fig. 7.c and 7.d on this page, the patient will announce their location, name, age and house number, then press the submit button. Thereafter, if the entered information is transmitted correctly, a message with the same content as shown in Fig. 7.e will be displayed otherwise an error message will be reported. In this case, the patient can resubmit the information by refreshing the page. After that the information entered will be sent to the support system via email. The received email is as 
shown in Fig. 7.f. This information is also stored in the system database as a table in accordance with Table 2.

\begin{tabular}{|c|c|c|c|c|}
\hline Date & Coordinate & Name & Age & $\begin{array}{c}\text { House } \\
\text { number }\end{array}$ \\
\hline $\begin{array}{c}2019-08-21 \\
09: 20: 33\end{array}$ & $\begin{array}{c}35.686827286363545 \\
51.38815820845946\end{array}$ & Ali & 28 & 32 \\
\hline
\end{tabular}

Table 2. The data sent is stored in the database.

In order to evaluate the proposed system, some of the system specifications presented by Manikandan (2017) that are measurable are compared with similar ones in the proposed system according to Table 3 . The most important strength of the Manikandan system is its accuracy. This advantage is due to the system's use of the ECG signal. Because this signal plays a key role in the diagnosis of heart disease. Of course, this system does not analyze the ECG signal, but rather asks the user to determine the outcome of the analysis. This is impossible in reality because the non-specialist user is unable to analyze it. On the other hand, the superiority of the proposed system is its compatibility with intelligent systems architecture, alerting, transmitting information, receiving and sending patient location.

\section{CONCLUSION}

In this study, a smart telecare system based on the intelligent system architectures provided by Gaur et al. (2015) is presented for the early diagnosis of acute cardiac syndrome. The inference method of this system is based on regression, which is trained using medical records and real samples. The accuracy of this system in the early diagnosis is $77.5 \%$ which is closed to that of the similar system proposed by Manikandan (2017). The reason of this difference is the lack of use of the ECG signal as input data in the proposed system. Regression which is used for classification and decision making in the ACS recognition has been proved to have enough accuracy in this making process which proved our assumption. The proposed system also sends the patient's location to the support system that is a very

\begin{tabular}{|c|c|c|}
\hline Specifications & $\begin{array}{c}\text { Manikandan's } \\
\text { system }\end{array}$ & $\begin{array}{c}\text { Our proposed } \\
\text { system }\end{array}$ \\
\hline Application & $\begin{array}{c}\text { Prediction of } \\
\text { heart attack }\end{array}$ & $\begin{array}{c}\text { Early diagnosis } \\
\text { of acute } \\
\text { Coronary } \\
\text { syndrome }\end{array}$ \\
\hline Platform & Web-based & Web-based \\
\hline $\begin{array}{c}\text { Decision making } \\
\text { Method }\end{array}$ & Bayesian & Regression \\
\hline $\begin{array}{c}\text { Number of } \\
\text { employed data }\end{array}$ & 14 & 17 \\
\hline Accuracy\% \\
\hline $\begin{array}{c}\text { Show results to the } \\
\text { user }\end{array}$ & Yes & Yes \\
\hline $\begin{array}{c}\text { Notification to } \\
\text { support system }\end{array}$ & No & Yes \\
\hline $\begin{array}{c}\text { Save user data in } \\
\text { database }\end{array}$ & Yes & Yes \\
\hline $\begin{array}{c}\text { Obtain, save and } \\
\text { send the user's } \\
\text { position }\end{array}$ & No & \\
\hline
\end{tabular}

Table 3. Comparison of the proposed system with that of Manikandan (2017) important feature as its main strength. Therefore, this system has better quality. The evaluation of the results shows that chest pain is the main symptom of the ACS Which corresponds to all medical sources. Improving the accuracy of this system by acquiring and analyzing more concerned user's real-time information and considering it in the telecare decision making, is a future step of this research. In addition, as some features such as ECG information have not been used to recognise the ACS in this research, future steps of this research will use them to improve the reliability of the diagnosis. Therefore, upgrading this system to a mobile system, including a ECG sensor, is a future prospect.

\section{REFERENCES}

Ahmad, Yaser Al, and Mohammed T. Ali. 2019. "Non-ST Elevation Myocardial Infarction: Diagnosis and Management." Myocardial Infarction, January. https://doi.org/10.5772/intechopen.76241.

Bellazzi, R., S. Montani, A. Riva, and M. Stefanelli. 2001. "Web-Based Telemedicine Systems for Home-Care: Technical Issues and Experiences." Computer Methods and Programs in Biomedicine 64 (3): 17587.

Berikol, Göksu Bozdereli, Oktay Yildiz, and I. Türkay Özcan. 2016. "Diagnosis of Acute Coronary Syndrome with a Support Vector Machine." Journal of Medical Systems 40 (4): 84. https://doi.org/10.1007/s10916016-0432-6.

Boulos, Maged N Kamel, Artur Rocha, Angelo Martins, Manuel Escriche Vicente, Armin Bolz, Robert Feld, Igor Tchoudovski, et al. 2007. "CAALYX: A New Generation of Location-Based Services in Healthcare." International Journal of Health $\begin{array}{llll}\text { Geographics } & 6 & \text { (March): } & 9 .\end{array}$ https://doi.org/10.1186/1476-072X-6-9.

Carral, Florentino, María del Carmen Ayala, Juan Jesús Fernández, Carmen González, Antonia Piñero, Gloria García, Concepción Cañavate, Ana Isabel Jiménez, and Concepción García. 2015. "Web-Based Telemedicine System Is Useful for Monitoring Glucose Control in Pregnant Women with Diabetes." Diabetes Technology \& Therapeutics 17 (5): 349-54. https://doi.org/10.1089/dia.2014.0223.

Del Hoyo, Javier, Pilar Nos, Raquel Faubel, Diana Muñoz, David Domínguez, Guillermo Bastida, Bernardo Valdivieso, Marisa Correcher, and Mariam Aguas. 2018. "A Web-Based Telemanagement System for Improving Disease Activity and Quality of Life in Patients With Complex Inflammatory Bowel Disease: Pilot Randomized Controlled Trial." Journal of Medical Internet Research 20 (11): e11602. https://doi.org/10.2196/11602.

Gaur, Aditya, Bryan Scotney, Gerard Parr, and Sally McClean. 2015. "Smart City Architecture and Its Applications Based on IoT." Procedia Computer Science, The 6th International Conference on Ambient Systems, Networks and Technologies (ANT-2015), the 5th International Conference on Sustainable Energy Information Technology (SEIT-2015), 52 (January): 1089-94.

https://doi.org/10.1016/j.procs.2015.05.122. 
Ghumbre, Shashikant, Chetan Patil, and Ashok Ghatol. 2011. "Heart Disease Diagnosis Using Support Vector Machine.” In .

Harrington, Peter. 2012. Machine Learning in Action. Manning Publications Co.

Krittanawong, Chayakrit, HongJu Zhang, Zhen Wang, Mehmet Aydar, and Takeshi Kitai. 2017. "Artificial Intelligence in Precision Cardiovascular Medicine." Journal of the American College of Cardiology 69 (21): 2657-64. https://doi.org/10.1016/j.jacc.2017.03.571.

Lamberti, Fabrizio, Bartolomeo Montrucchio, Bartolomeo Montrucchio, and Claudio Zunino. 2002. "A WebBased Architecture Enabling Multichannel Telemedicine Applications." Journal of Systemics, Cybernetics and Informatics 1 (1).

Manikandan, S. 2017. "Heart Attack Prediction System." 2017 International Conference on Energy, Communication, Data Analytics and Soft Computing (ICECDS), 81720. https://doi.org/10.1109/icecds.2017.8389552.

Mohanty, Saraju P. 2016. "Everything You Wanted to Know about Smart Cities: The Internet of Things Is the Backbone." IEEE Consumer Electronics Magazine 5: 60-70. https://doi.org/10.1109/MCE.2016.2556879.

Olayinka,T.C. , Olayinka A.S , Oladimeji O.R. 2018. "Framework for Web-Based and Desktop-Based Telemedicine System." 2018. https://www.edouniversity.edu.ng/oer/journal/framew ork_for_web-based_and_desktopbased_telemedicine_system.

Purusothaman, G., and P. Krishnakumari. 2015. "A Survey of Data Mining Techniques on Risk Prediction: Heart Disease." Indian Journal of Science and Technology 8 (12).

Safdari, Reza, Niloofar Masouri, Marjan Ghazi Saeedi, Roya Sharifian, Ahmad Soltani, and Leila Shahmoradi. 2012. "Wireless and Mobile Systems in Telemedicine." ISMJ 15 (4): 327-38.

Soltani, Lida, Ali Ravari, and Sakineh Sabzevari. 2016. "Relationship between Prodromal (Warning) Symptoms and Referring Time in Patients with Myocardial Infarction." Iranian Journal of Cardiovascular Nursing 4 (4): 22-31.

Sundaravadivel, P., E. Kougianos, S. P. Mohanty, and M. K. Ganapathiraju. 2018. "Everything You Wanted to Know about Smart Health Care: Evaluating the Different Technologies and Components of the Internet of Things for Better Health." IEEE Consumer Electronics Magazine 7 (1): 18-28. https://doi.org/10.1109/MCE.2017.2755378.

VanHouten, Jacob P., John M. Starmer, Nancy M. Lorenzi, David J. Maron, and Thomas A. Lasko. 2014. "Machine Learning for Risk Prediction of Acute Coronary Syndrome." AMIA Annual Symposium Proceedings 2014 (November): 1940-49. 